\title{
Pengembangan Prosedur Operasional Standar (POS) Room Attendant Pada Mata Kuliah Tata Graha, Program Studi Perhotelan DIII di Universitas Pendidikan Ganesha
}

\author{
Oleh \\ Ni Made Ary Widiastini \\ Nyoman Dini Andiani
}

\begin{abstract}
Abstrak
Penelitian ini bertujuan untuk mengembangkan prosedur operasional standar yang dapat diterapkan pada mata kuliah Tata Graha pada Program Studi Perhotelan Diploma III, untuk sub mata kuliah room attendant. Tuntutan pekerjaan yang semakin tinggi di hotel, khususnya pada departemen tata graha (housekeeping) menyebabkan lulusan harus memahami standar kerja atau prosedur operasional standar hotel yang selalu mengalami perubahan dari waktu ke waktu demi menciptakan kualitas produk dan layanan hotel. Pada kesempatan ini peneliti melakukan penelitian pada hotel yang berada pada manajemen starwood yang berlokasi di kawasan pariwisata Nusa Dua. Berdasarkan observasi dan wawancara diperoleh dua puluh standar yang dapat diadopsi untuk digunakan sebagai acuan dalam proses belajar mengajar. Adapun prosedur operasional standar untuk petugas kamar (room attendant) yang dimaksud adalah grooming, report to manager, answer telephone, assignments, cleaning supplies caddie, entering guest room, guest in room, room cleaning order, check out room, clean floor, making bed, clean toilet, clean shower wall, amanities, clean furniture, vacuum room, leave room, return cleaning supplies, turn in keys, end of shift.
\end{abstract}

Kata kunci : prosedur operasional standar, housekeeping, room attendant.

\section{Development of Standard Operating Procedures (POS) of Room Attendant, on housekeeping lesson, DIII Hotel Hospitality Program, Universitas Pendidikan Ganesha}

\begin{abstract}
This study aims to develop standard operational procedures applicable to the course of housekeeping's lesson in Diploma III Hospitality Studies Program, specially about room attendant. The increasingly high demand for jobs in hotels, particularly in housekeeping departments, has meant that graduates must understand the standard of work or standard hotel operating procedures that are constantly increasing the quality and service of hotels. On this occasion researchers conducted research on hotels that are on starwood management in Nusa Dua tourism area. Based on observations and interviews theres are twenty standard operational procedure that can be adopted to be used as a reference in the learning process i.e grooming, report to manager, answer telephone, assignments, cleaning supplies caddie, entering guest room, guest in room, room cleaning order, check out room, clean floor, making bed, clean toilet, clean shower wall, amanities, clean furniture, vacuum room, leave room, return cleaning supplies, turn in keys, end of shift.
\end{abstract}

Key words : standard operational procedure, housekeeping, room attendant. 


\section{Pendahuluan}

Prosedur Operasional Standar (POS) adalah sebuah rangkaian instruksi kerja yang disusun secara sistematis dan tertulis yang dibuat oleh pihak yang berwenang dan berfungsi untuk mengatur setiap individu yang terlibat dalam suatu organisasi atau kelompok kerja atau lembaga atau perusahaan. Instruksi kerja yang disusun selanjutnya dibakukan oleh suatu unit organisasi dengan tujuan semua pihak yang ada di dalam suatu organisasi tersebut mengikuti aturan kerja yang telah ditetapkan. Secara umum prosedur operasional standar berisikan proses penyelenggaraan administrasi organisasi, bagaimana dan kapan suatu hal harus dilakukan, dimana dan siapa yang wajib melakukannya. Dalam hal ini, prosedur operasional standar merupakan suatu pedoman atau acuan untuk melaksanakan tugas pekerjaan sesuai dengan fungsi tertentu. Hal tersebut sejalan dengan pandangan Suzanne, John dan Norman (2005: 231-241) bahwa di dalam memainkan peran integral, manajemen harus menunjukkan kualitas kerja secara total yang dapat meningkatkan konsistensi output, efisiensi, dan tingkat belajar dari suatu proses. Diharapkan prosedur operasional standar dapat memberikan manfaat, yakni sebagai pedoman kerja suatu organisasi, meminimalisasi tingkat kesalahan dalam bekerja, semua pihak yang terlibat di dalam organisasi mampu mengetahui dan memahami beban kerja dan tanggungjawabnya masing-masing, meningkatkan akuntabilitas pelaksanaan tugas, dan mampu menciptakan ukuran standar kinerja.

Program Studi Diploma III Perhotelan, Universitas Pendidikan Ganesha merupakan salah satu program studi yang wajib memiliki prosedur operasional standar dalam melaksanakan perkuliahan, khususnya pada ke- giatan praktek. Salah satu mata kuliah yang wajib memiliki prosedur operasional standar adalah Tata Graha. Mata kuliah tata graha adalah mata kuliah yang membahas ruang lingkup kerja yang dilakukan oleh petugas house keeping dalam hotel, floor section atau room section, linen dan laundry, florist dan gardener. Adapun hal spesifik yang harus diketahui dan dipahami oleh mahasiswa melalui mata kuliah Tata Graha meliputi pengenalan posisi house keeping dalam hotel serta bagianbagiannya, struktur organisasi, pengenalan jenis lantai dan dinding, pengenalan cleaning equipment, pengenalan cleaning supplies, pengenalan serta praktik penyiapan kamar, pencatatan status kamar, linen, laundry, floris, gardener, serta manajemen tata graha. Salah satu prosedur operasional standar yang wajib dimiliki oleh setiap hotel maupun lembaga pendidikan perhotelan adalah standar dalam penyiapan kamar tamu yang dalam penerapannya dilakukan oleh petugas yang disebut dengan room attendant. Seorang room attendant senantiasa dituntut untuk mampu menyiapkan kamar yang bersih, menarik, dan memiliki nilai jual tinggi. Oleh sebab itu, setiap room attendant harus memahami prosedur penyiapan ruang kamar dengan baik agar mampu menghasilkan kamar yang memiliki nilai jual dan menguntungkan hotel.

Memahami beratnya beban pekerjaan seorang room attendant, maka seseorang yang mau bekerja pada bidang kerja Tata Graha/ Housekeeping di hotel harus memahami prosedur operasional standar yang ada di hotel, termasuk bagi mahasiswa yang ingin melaksanakan on the job trainee pada sebuah hotel. Tingginya tuntutan hotel, maka pada kesempatan ini dilakukan penelitian pengembangan prosedur operasional standar untuk mata kuliah Tata 
Graha pada sub mata kuliah kamar (room).

\section{Pembahasan}

Ruang Lingkup Kerja Room Attendant Pada Departemen Housekeeping di Hotel

Kamar sebagai produk utama hotel harus mampu disiapkan dengan baik oleh pihak room attendant sebagai bagian dari housekeeping. Secara umum terdapat empat kriteria kamar yang wajib diperhatikan oleh room attendant diantaranya (1) Cleanlines yang berarti kamar harus bersih dan hygiene sehingga tamu merasa sehat bila ada di kamar tersebut. Disamping kebersihan ruangan itu dijaga, perlu juga diperhatikan sirkulasi udara dan penyinaran matahari yang cukup dalam kamar sehingga tamu dapat merasa nyaman; (2) Comfortable, artinya kamar harus dapat membuat tamu yang menginap di hotel tersebut merasa nyaman. Keadaan kamar harus diperhatikan seperti tata letak meja, kursi, tempat tidur dan perlengkapan lainnya. Fasilitas-fasilitas ini diletakkan dengan baik dan senyaman mungkin, sehingga tamu yang menginap tidak kesulitan untuk lalu lalang di kamar; (3) Attractive, yakni kamar harus dapat membuat tamu menjadi tertarik untuk menginap. Dalam hal ini sangat perlu diperhatikan desain kamar, dalam hal ini desain kamar seharusnya sesuai dengan pangsa pasa hotel; (4) Safety, yang artinya kamar harus dapat membuat tamu yang menginap merasa aman. Perlu diperhatikan peralatan dan perlengkapan elektronik yang ada di dalam kamar, jangan sampai dapat membuat tamu celaka. Begitu pula dengan kamar mandi, jangan menggunakan lantai yang licin yang juga dapat membahayakan tamu yang menginap.

Ben Walker (2012) dalam laporannya tentang pentingnya peranan housekeeping pada hotel menjelaskan posisi housekeeping sebagai berikut.

"To overlook the importance of housekeeping is a huge mistake since the rooms department generates the most profit for a hotel and the cleanliness and condition of bedrooms are the most important factors in customer satisfaction ratings. These facts have not gone unnoticed by budget and economy hotel brands - essentially bedroom-only products. It is encouraging that in this sector a few head housekeepers have successfully made the transition to general managers, and it is hoped that some of them will take the opportunity to migrate over to traditional full-service hotels".

Dijelaskan bahwa mengabaikan peranan housekeeping dalam hotel merupakan hal yang salah, karena karena departemen kamar mampu menghasilkan keuntungan paling banyak untuk sebuah hotel. Untuk menciptakan keuntungan yang besar, petugas kamar (room attendant) harus memerhatikan kebersihan dan kondisi kamar tidur sehingga tercipta kepuasan pelanggan/tamu yang menginap. Bahkan apabila seorang housekeeper khususnya room attendant mampu bekerja dengan baik dan memberikan banyak keuntungan bagi hotel, mereka mampu mencapai posisi manajemen di hotel. Housekeeping sebagai bagian penting dalam hotel karena bertugas untuk menyiapkan ruangan hotel yang dapat dijual oleh pihak kantor depan (front office) maupun pemasaran (sales).

Petugas housekeeping khususnya yang menangani kamar (room attendant) wajib memerhatikan segala sesuatu yang harus dilakukan dalam 
menyiapkan kamar yang bersih, rapi, aman, nyaman dan menarik. Schneider, Tucker \& Scoviak-Lerner (1999) menyebutkan bahwa "The housekeeping staff responsible for servicing the guest rooms must ensure that the correct level of amenities are replaced in rooms according to the required standards which include completing the servicing process within a specified time". Dalam hal ini dijelaskan bahwa petugas housekeeping khususnya room attendant memiliki bertanggung jawab untuk melayani kamar tamu, serta harus memastikan bahwa fasilitas yang tersedia atau disiapkan dalam kamar sudah sesuai dengan standar yang ditentukan oleh pihak manajemen hotel.

Room attendant sebagai petugas yang penting dalam menyiapkan produk utama hotel yakni kamar, sebagaimana pandangan Angela Knox, Chris Warhurst, Dennis Nickson dan Eli Dutton (2015) menjelaskan bahwa secara keseluruhan, keterampilan yang dibutuhkan petugas kamar (room attendant) lebih memperhatikan kepribadian, kesabaran terhadap jam kerja yang dibutuhkan, perhatian terhadap detail kamar dan kemampuan untuk bekerja keras. Meskipun untuk menjadi room attendant memerlukan pelatihan formal atau pendidikan yang relatif sedikit, pada kenyataannya rutinitas kerja lah yang mampu menjadikan mereka dapat bekerja dengan baik dan menjadi profesional. Hal tersebut disebabkan karena pekerjaan yang diambil secara rutin oleh room attendant berimplikasi pada kepekaan mereka terhadap hal-hal kecil yang seharusnya mendapatkan perhatian secara detail sehingga mampu menyiapkan kamar yang baik dan sesuai dengan harapan tamu yang menginap.

Praktiknya, semua petugas kamar (room attendant) harus mampu memastikan pada awal shift bahwa mereka memiliki peralatan dan alat yang benar yang diperlukan untuk menyelesaikan tugas sehari-hari mereka. Selain itu, semua kamar harus dibersihkan dengan cara yang aman dan cerdas sesuai standar hotel. Selanjutnya, setelah selesai membersihkan ruangan, petugas kamar harus memastikan bahwa status kamarnya telah diperbarui. Pembersihan ruangan kamar tamu secara umum dua kali dengan pembagian waktu kerja menjadi tiga sift kerja yang telah diatur oleh atasan mereka. Pada umumnya pembersihan kamar dilakukan pada pagi dan sore hari, sementara pada malam hari biasanya ditangani oleh supervisor yang ditunjuk oleh executive housekeeper untuk berkeliling mengecek kamar-kamar, seandainya ada tamu yang membutuhkan kamarnya untuk dibersihkan atau ditangani.

Pengembangan Prosedur Operasional Standar (POS) Room Attendant Pada Program Studi Perhotelan DIII

Prosedur operasional standar (POS) untuk room attendant yang telah dimiliki oleh Program Studi Perhotelan DIII dapat dipaparkan sebagai berikut:

1. Tugas: Membersihkan dan memelihara semua kamar dan area yang ditentukan, dan memberikan layanan pribadi untuk para tamu.

2. Keterampilan yang wajib dimiliki :

a) Mampu menggunakan peralatan kebersihan.

b) Mampu menggunakan bahan pembersih dan perlengkapan.

c) Tahu cara membersihkan toilet dan urinals dengan benar.

d) Tahu bagaimana menyiapkan tempat tidur dengan benar.

3. Pengetahuan yang wajib dimiliki:

a) Kebersihan pribadi dan penampilan.

b) Organisasi hotel.

c) Tata letak hotel. 
d) Kebijakan dan prosedur hotel.

e) Membersihkan sesuai prosedur dan teknik.

4. Urutan kerja.

a) Set-up kamar.

b) Penggunaan bahan kimia.

5. Tugas dan tanggungjawab:

a) Bertanggung jawab atas kebersihan dan perawatan semua ruangan dan area yang ditugaskan.

b) Menerima kunci kamar dan instruksi dari supervisor sebelum mulai bekerja dan mengembalikan kunci setelah shift berakhir.

c) Pada pagi hari, cek hunian kamar di bagiannya dan laporkan ke supervisor.

d) Menerima peralatan, perlengkapan pembersih dan linen dari floor supervisor.

e) Cek persediaan tamu dan kondisi kamar.

f) Laporkan barang yang hilang atau rusak yang ditemukan di kamar atau tempatkan secara langsung ke supervisor.

g) Siapkan kereta anak laki-laki dengan persediaan sebelum membersihkan dan membuat kamar setiap hari.

h) Melaporkan dan menyerahkan artikel yang hilang dan ditemukan kepada supervisor.

i) Membersihkan dan membuat kamar sesuai instruksi dan menetapkan standar.

- Bangun tempat tidur - ganti sprei dan sarung bantal dan jika perlu juga ganti selimut dan bed cover.

- Bersihkan lantai dengan penyapu karpet atau vakum.

- Asbak debu dan pembersih sampah dan sampah.

- Ganti handuk dan pasangkan persediaan seperti korek api, stasioner, tisu wajah, kertas toilet, dan sabun.

- Isi gelas air isi ulang dengan air es.

- Pintu lemari bersih, dinding, plafon, grill AC, cermin, jendela, rak, dan kertas.

- Kamar mandi bersih: dinding, bak mandi, wastafel, cermin, counter, urinal, mangkuk toilet, dan lantai.

- Ganti handuk dan sabun isi ulang.

j) Cek dengan Supervisor untuk melihat apakah ada persyaratan khusus.

k) Memberikan perhatian khusus pada ruangan VIP.

1) Siapkan tempat tidur tambahan dan ikuti permintaan khusus dari tamu seperti handuk ekstra, sabun, korek api dll.

m) Menjaga kebersihan di area tamu dan servis.

n) Melaporkan adanya orang yang mencurigakan di hotel kepada supervisor.

o) Melengkapi laporan tugas anak laki-laki setiap hari dan melaporkan persediaan dan konsumsi linen.

p) Memastikan jadwal mingguan untuk pekerjaan pembersihan khusus dilakukan dengan benar.

q) Melaporkan masalah atau persyaratan untuk tamu atau area lain kepada supervisor yang meneruskan informasi ke shift berikutnya.

Pengembangan Prosedur Operasional Standar (POS) Room Attendant Pada Program Studi Perhotelan DIII, berdasarkan hasil observasi dan wawancara yang dilakukan pada salah satu starwood hotel di Nusa Dua dapat dipaparkan sebagai berikut. 


\begin{tabular}{|c|c|c|c|}
\hline No & Aspek & Tujuan & Prosedur \\
\hline 1 & Grooming & $\begin{array}{l}\text { Mematu } \\
\text { hi } \\
\text { standar } \\
\text { perawat- } \\
\text { an yang } \\
\text { dibutuh- } \\
\text { kan }\end{array}$ & 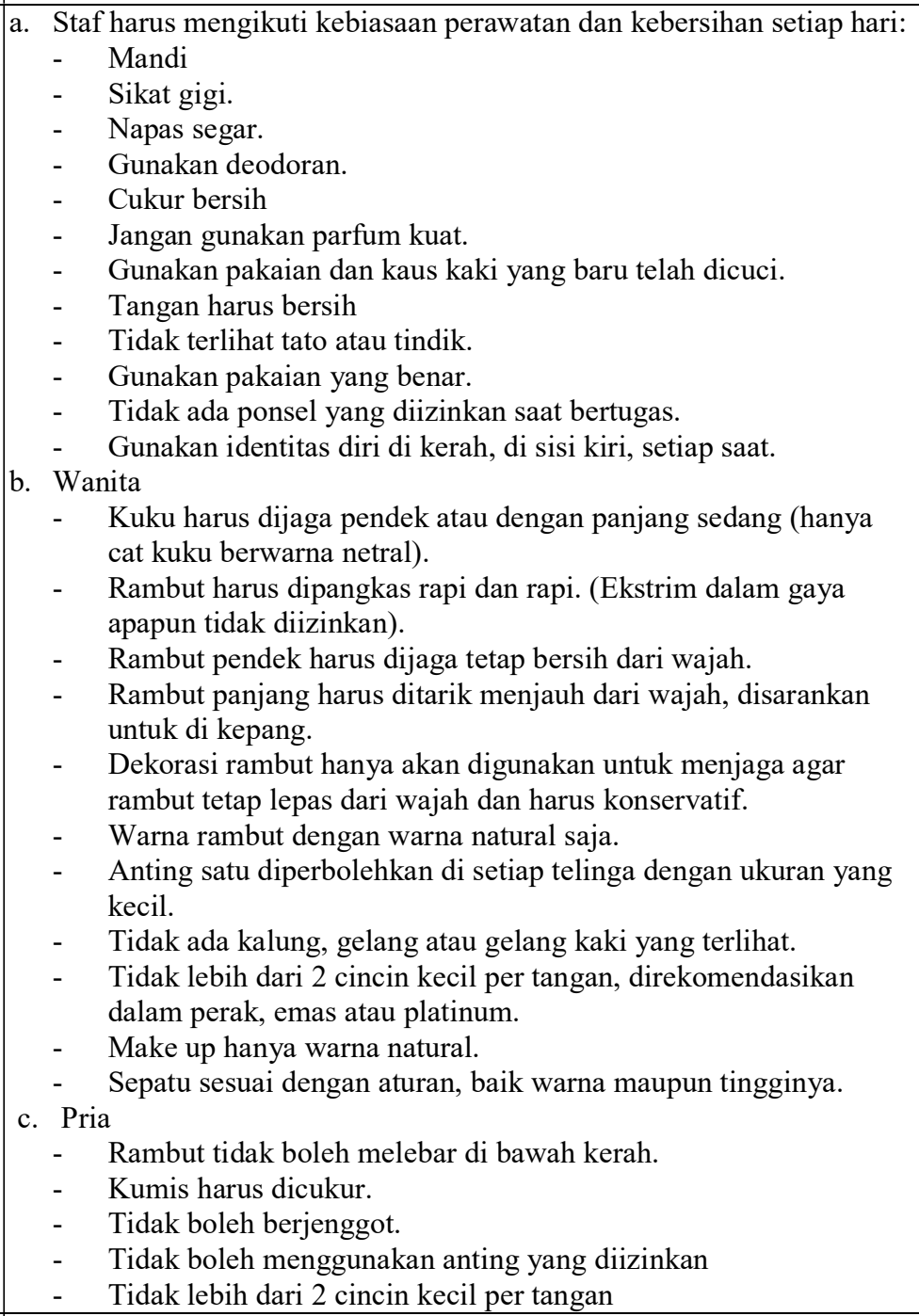 \\
\hline 2 & $\begin{array}{l}\text { Report to } \\
\text { Manager }\end{array}$ & $\begin{array}{l}\text { Melapor } \\
\text { kan } \\
\text { segala } \\
\text { kegiatan } \\
\text { dan } \\
\text { tindakan } \\
\text { kepada } \\
\text { atasan }\end{array}$ & $\begin{array}{l}\text { a) Staf diwajibkan selalu hadir tepat waktu, apabila ada yang melanggar } \\
\text { diberikan beberapa waktu untuk berubah. } \\
\text { b) Staf wajib masuk melalui pintu masuk staf, tidak boleh melalui pintu } \\
\text { masuk tamu. } \\
\text { c) Apabila ada yang mengalami masalah kehadiran karena suatu dan } \\
\text { lain hal, pimpinan harus diberitahu maksimal dua jam sebelum ada } \\
\text { perubahan jadwal. } \\
\text { d) Bagi karyawan yang sakit harus memberitahu pimpinan maksimal } \\
\text { dua jam sebelum jam kerja dimulai. } \\
\text { e) Keterlambatan tanpa ada informasi dikenakan tindak kedisiplinan } \\
\text { f) Setiap karyawan harus melapor kepada pimpinan masing-masing } \\
\text { untuk tugas yang telah dilaksanakan. } \\
\text { g) Tugas harian harus selesai dalam waktu yang dibutuhkan. } \\
\text { h) Tugas harian harus diserahterimakan sebelum pergi. }\end{array}$ \\
\hline 3 & $\begin{array}{l}\text { Answer } \\
\text { Telephone }\end{array}$ & $\begin{array}{l}\text { Memaha } \\
\text { mi cara } \\
\text { berbicara } \\
\text { kepada } \\
\text { tamu } \\
\text { dengan }\end{array}$ & $\begin{array}{l}\text { a) Semua panggilan harus segera dijawab } \\
\text { b) Telepon akan dijawab dengan: " Good ......, thank you for calling } \\
\text { Housekeeping, this is (name) how may I assist you? Jika telepon } \\
\text { menunjukkan nama tamu ; ...how may I assist you Mr./ Ms. ... } \\
\text { c) Selalu jawab dengan senyuman, bicaralah dengan jelas dan hindari } \\
\text { kata-kata atau kalimat slang seperti: ya, lah dan ok. Lebih baik }\end{array}$ \\
\hline
\end{tabular}




\begin{tabular}{|c|c|c|c|}
\hline & & $\begin{array}{l}\text { baik, } \\
\text { benar } \\
\text { dan } \\
\text { sesuai } \\
\text { kebutuh- } \\
\text { an }\end{array}$ & $\begin{array}{l}\text { gunakan "certainly" and "it is my pleasure". } \\
\text { d) Usahakan untuk tidak membiarkan tamu menunggu terlalu lama, } \\
\text { segera bero respon dan selalu katakan terima kasih karena tamu telah } \\
\text { mau menunggu. } \\
\text { e) Sebelum mentransfer pemanggil, beritahu tamu tentang transfer dan } \\
\text { siapa anda mentransfernya. " It will be my pleasure to connect your } \\
\text { call ". } \\
\text { f) Mengambil dan mencatat informasi permintaan tamu, yang terdiri } \\
\text { dari nama tamu, nomor kamar atau ekstensi, ermintaan atau item, } \\
\text { waktu yang diminta, tanggal, waktu memulai telepon, komentar, dan } \\
\text { waktu selesai } \\
\text { g) Ulangi semua informasi kembali ke tamu untuk verifikasi. } \\
\text { h) Setelah menerima permintaan tamu, berikan waktu pengiriman } \\
\text { kepada tamu. }\end{array}$ \\
\hline 4 & $\begin{array}{l}\text { Assignmen } \\
\text { ts }\end{array}$ & $\begin{array}{l}\text { Aagar } \\
\text { semua } \\
\text { staf tahu } \\
\text { tugas } \\
\text { dan } \\
\text { tanggung } \\
\text { jawab- } \\
\text { nya } \\
\text { masing- } \\
\text { masing }\end{array}$ & $\begin{array}{l}\text { a) Semua Room Attendants memiliki tugas kamar. Sebelum naik ke } \\
\text { lantai, pergilah ke kantor Housekeeping untuk mengambil daftar } \\
\text { lembar tugas; nama tamu, nomor kamar dan status kamar. } \\
\text { b) Kaji ulang ulasan dan catatan pada lembar tugas informasi tambahan } \\
\text { yang diberikan oleh koordinator, supervisor atau pimpinan anda. } \\
\text { c) Jangan pernah meninggalkan atau menghilangkan lembaran tugas } \\
\text { karena berisi informasi pribadi tamu. } \\
\text { d) Melaporkan item pesanan pekerjaan apapun pada lembar tugas. } \\
\text { e) Jumlah kamar yang terdaftar dan penugasan wilayah akan bervariasi. } \\
\text { f) Jika terjadi perubahan status, catatlah perubahan pada lembar kerja } \\
\text { Anda. } \\
\text { g) Bila semua tugas telah dilakukan, kembalikan lembar tugas kepada } \\
\text { pimpinan. }\end{array}$ \\
\hline 5 & $\begin{array}{l}\text { Cleaning } \\
\text { Supply } \\
\text { Caddie }\end{array}$ & $\begin{array}{l}\text { Tersedia } \\
\text { nya } \\
\text { kebutuh- } \\
\text { an } \\
\text { pember- } \\
\text { sih setiap } \\
\text { saat } \\
\text { sesuai } \\
\text { dengan } \\
\text { kebutuh- } \\
\text { an }\end{array}$ & $\begin{array}{l}\text { a) Pastikan persediaan bahan pembersih tersedia dalam jumlah yang } \\
\text { dibtuhkan setiap saat. } \\
\text { b) Pastikan botol untuk yang diisi dengan bahan pembersih berfungsi } \\
\text { dnegan baik } \\
\text { c) Bahan kimia yang perlu disiapkan, yakni window cleaner, all- } \\
\text { purpose disinfectant, room deodorizer, toilet bowl cleaner and } \\
\text { disinfectant (non-corrosive). } \\
\text { d) Alat pembersih yang dibutuhkan yakni sponge, floor cloth, toilet } \\
\text { brush, pair of rubber gloves, clean rags/clothes, dan floor sweeper. } \\
\text { e) Perlu pelatihan penggunaan bahan kimia agar mampu menggunakan } \\
\text { dengan tepat dan cermat. }\end{array}$ \\
\hline 6 & $\begin{array}{l}\text { Entering } \\
\text { Guest } \\
\text { Room }\end{array}$ & $\begin{array}{l}\text { Setiap } \\
\text { staff tahu } \\
\text { cara } \\
\text { masuk } \\
\text { ke } \\
\text { ruangan } \\
\text { kamar } \\
\text { tamu } \\
\text { dengan } \\
\text { baik dan } \\
\text { sopan, } \\
\text { tanpa } \\
\text { menim- } \\
\text { bulkan } \\
\text { masalah } \\
\text { atau } \\
\text { meng- } \\
\text { ganggu } \\
\text { tamu }\end{array}$ & $\begin{array}{l}\text { a) Setiap room attendant harus mengetahui nama tamu terlebih dahulu } \\
\text { sebelum membunyikan bel. } \\
\text { b) Room attendant berdiri di depan pintu kamar tamu. } \\
\text { c) Bunyikan bel dengan } 3 \text { kali dan beri waktu untuk bel yang kedua di } \\
\text { antara dering bel. } \\
\text { d) Jika ada tamu, room attendant harus menyapa tamu dengan nama } \\
\text { dan mengenalkan dirinya dan menjelaskan apa yang akan dia } \\
\text { lakukan } \\
\text { e) Jika tidak ada jawaban dan tidak ada tamu, room attendant membuka } \\
\text { pintu perlahan dan memasuki ruangan. }\end{array}$ \\
\hline 7 & Guest & Petugas & a) Saat memasuki kamar tamu, tanyakan apakah mereka ingin Anda \\
\hline
\end{tabular}




\begin{tabular}{|c|c|c|c|}
\hline & room & $\begin{array}{l}\text { memaha } \\
\text { mi cara } \\
\text { bersikap } \\
\text { ketika } \\
\text { tamu ada } \\
\text { di dalam } \\
\text { kamar- } \\
\text { nya. }\end{array}$ & $\begin{array}{l}\text { kembali nanti. } \\
\text { b) Jika tamu menolak layanan, tawarkan kepada tamu, yakni handuk } \\
\text { segar, fasilitas kamar mandi, dan guest supplies lainnya. } \\
\text { c) Saat tamu menyarankan agar Anda masuk dan membersihkan } \\
\text { ruangannya, ikuti prosedur ini: } \\
\text { - Beritahu supervisor bahwa anda berada pada ruangan yang ada } \\
\text { tamu di dalamnya. } \\
\text { - Biarkan pintu tetap dalam keadaan terbuka. } \\
\text { - Bila telah selesai bekerja dan meninggalkan ruangan, } \\
\text { informasikan kembali supervisor. } \\
\text { - Prosedur tersebut bertujuan untuk melindungi room attendant, } \\
\text { jadi wajib dilakukan dengan baik dan benar. } \\
\text { d. Jangan pernah mengizinkan karyawan atau teman lain masuk ke } \\
\text { ruangan kecuali diberi wewenang oleh floor supervisor. Semua tamu } \\
\text { disambut dengan salam dan senyum. Perhatikan kontak mata dan } \\
\text { postur tubuh saat berinteraksi dengan tamu. }\end{array}$ \\
\hline 8 & $\begin{array}{l}\text { Room } \\
\text { Cleaning } \\
\text { Order }\end{array}$ & $\begin{array}{l}\text { Member- } \\
\text { sihkan } \\
\text { ruangan } \\
\text { kamar } \\
\text { sesuai } \\
\text { dengan } \\
\text { kebutuh- } \\
\text { an dan } \\
\text { prosedur }\end{array}$ & $\begin{array}{l}\text { a) Pastikan kamar dibersihkan berdasarkan prioritas kategori. } \\
\text { b) Periksa lembar tugas dan mulai dalam urutan: } \\
\text { - Check-out Rooms } \\
\text { - Early Service Request rooms } \\
\text { - V.I.P rooms } \\
\text { - Occupied Stay-Over rooms }\end{array}$ \\
\hline 9 & $\begin{array}{l}\text { Check out } \\
\text { room }\end{array}$ & $\begin{array}{l}\text { Memasti } \\
\text { kan } \\
\text { barang } \\
\text { tamu } \\
\text { yang } \\
\text { kemung- } \\
\text { kinan } \\
\text { terting- } \\
\text { gal; } \\
\text { sebelum } \\
\text { tamu } \\
\text { check } \\
\text { out }\end{array}$ & $\begin{array}{l}\text { a. Pastikan semua kamar diperiksa pada saat check-out: } \\
\text { - Hidupkan semua lampu dan buka semua laci. } \\
\text { - Pastikan semua lampu berfungsi dengan baik. } \\
\text { - } \text { Pastikan semua laci terbuka dengan mudah dan kosong } \\
\text { - } \text { Hidupkan televisi dan radio dan periksa apakah sudah sesuai, lalu } \\
\text { matikan. } \\
\text { - Periksa perabotan dan / atau peralatan yang hilang dan laporkan } \\
\text { barang yang hilang ke housekeeping segera. Periksa perbaikan } \\
\text { yang diperlukan dan laporkan ke floor supervisor atau catat } \\
\text { lembar tugas. } \\
\text { b. Segera bawa barang lost and found ke office housekeeping, jangan } \\
\text { menunggu sampai jam kerja berakhir. } \\
\text { c. Mohon sampaikan semua permintaan perawatan kepada koordinator } \\
\text { housekeeping. }\end{array}$ \\
\hline 10 & Clean Floor & $\begin{array}{l}\text { Menjaga } \\
\text { keadaan } \\
\text { lantai } \\
\text { tetap } \\
\text { bersih } \\
\text { sepan- } \\
\text { jang } \\
\text { waktu }\end{array}$ & $\begin{array}{l}\text { a) Pastikan lantai bebas dari kotoran, debu, rambut, jejak kaki, bekas } \\
\text { goresan, dan noda. } \\
\text { b) Sapu kotoran dan debu, perhatikan sudut dan belakang toilet.. } \\
\text { c) Gunakan lap basah jika terdapat benda lengket untuk mengambil } \\
\text { bulu. } \\
\text { d) Lap jika ada bekas goresan. } \\
\text { e) Area kamar mandi seluruh di bersihkan atau vakum sebelum } \\
\text { mengepel lantai. } \\
\text { f) Setelah dikeringkan, periksa kembali kebersihannya, perhatikan } \\
\text { secara khusus terutama jika terdapat rambut. }\end{array}$ \\
\hline 11 & $\begin{array}{l}\text { Making } \\
\text { Bed }\end{array}$ & $\begin{array}{l}\text { Menyiap } \\
\text { kan } \\
\text { tempat } \\
\text { tidur } \\
\text { yang } \\
\text { bersih, } \\
\text { rapi } \\
\text { menarik } \\
\text { dan }\end{array}$ & $\begin{array}{l}\text { a) Bawa barang bawaan tamu ke tempat tidur dan letakkan di bangku } \\
\text { sebelum mengambil linen. } \\
\text { b) Strip bed dari linen kotor. } \\
\text { c) Pastikan semua linen segar bersih, kencang, dan bebas dari robekan, } \\
\text { dan noda. } \\
\text { d) Bila linen rusak, jangan meletakkannya melalui tempat linen, tapi } \\
\text { sisihkan agar tidak tercampur dengan linen yang bagus. } \\
\text { e) Ambil selimut dan bantal dan letakkan di kursi/bangku, bukan di } \\
\text { lantai. }\end{array}$ \\
\hline
\end{tabular}




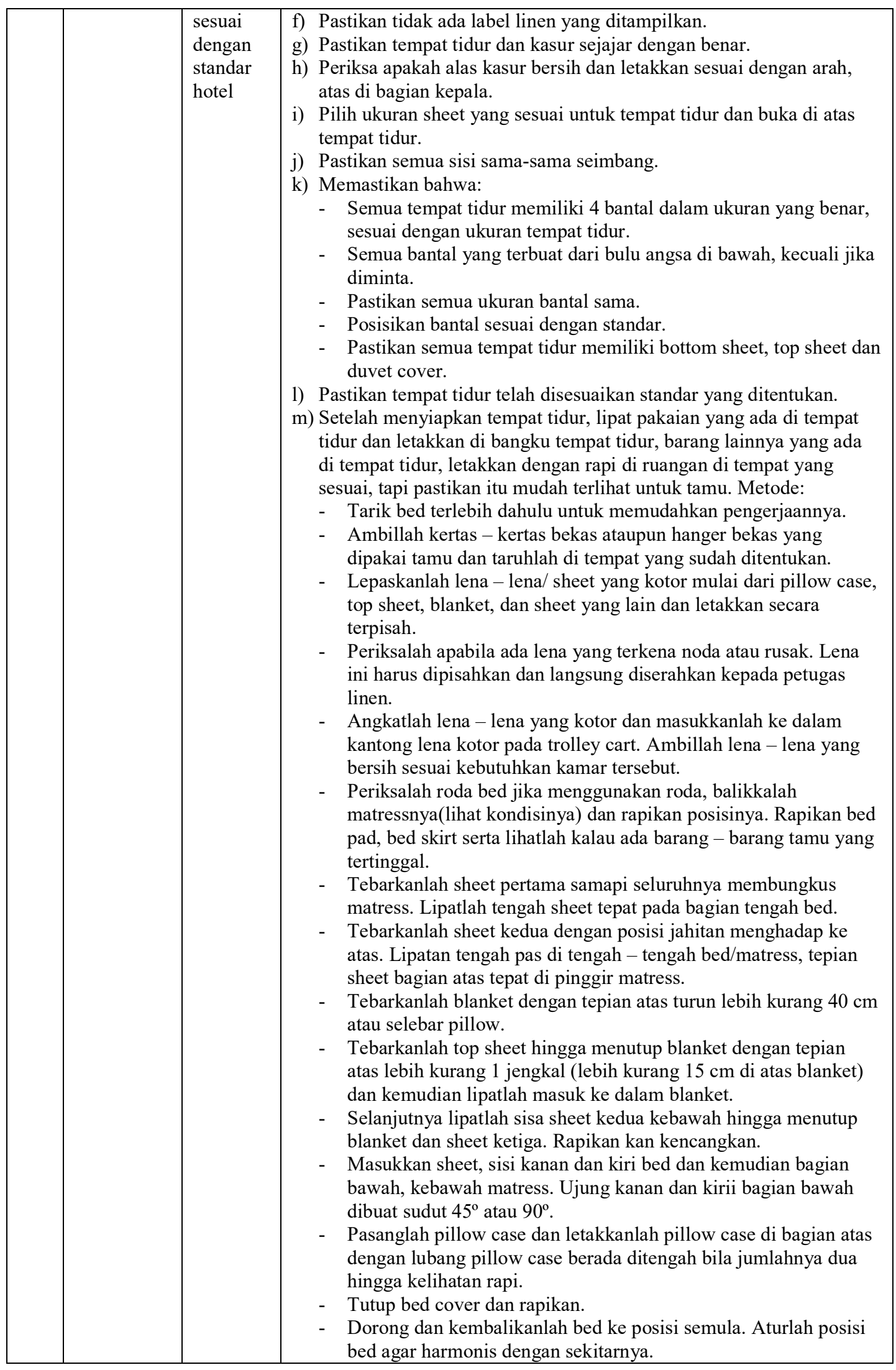




\begin{tabular}{|c|c|c|c|c|}
\hline & & & o) & $\begin{array}{l}\text { Pasang pillow case dengan tahapan: } \\
\text { - Ambillah pillow case, bukalah lipatannya dan letakkan dulu di } \\
\text { atas bed. } \\
\text { - Ambillah pillow, lipatlah salah satu ujungnya menjadi dua } \\
\text { bagian. } \\
\text { - Ambillah pillow case dan masukkan pillow yang masih terlipat } \\
\text { tadi hingga sampai ujung pillow case dan lepaslah pillow } \\
\text { tersebut. Rapikan kedua ujungnya. } \\
\text { - Tariklah tangan yang ikut masuk ke dalam pillow case sambil } \\
\text { merapikan sudut dan sisi pillow yang tertinggal. } \\
\text { - Pegang kedua ujung pillow case tersebut, goyang - goyangkan, } \\
\text { hentak - hentakkan untuk memposisiskan pillow case tersebut } \\
\text { dengan benar. Lipatlah kedalam salah satu sisi dan rapikanlah. } \\
\text { - Masukkan pula sisi yang lainnya ke dalam pillow case, rapikan } \\
\text { dan peganglah ujungnya, angkat, rapikan dan letakkan di atas } \\
\text { bed. } \\
\text { Pasang duvet dengan cara: } \\
\text { - Pasang sarung duvet (duvet case) pada duvet } \\
\text { - Tebarkanlah duvet pada bed } \\
\text { - Aturlah bagian bawah agar sesuai dengan bed. } \\
\text { - Tariklah ke atas, aturlah bagian atas agar sesuai dengan bed dan } \\
\text { rapikan tepi-tepinya }\end{array}$ \\
\hline 12 & Clean toilet & $\begin{array}{l}\text { Memasti } \\
\text { kan toilet } \\
\text { selalu } \\
\text { dalam } \\
\text { keadaan } \\
\text { bersih }\end{array}$ & $\begin{array}{l}\text { h) } \\
\text { i) } \\
\text { j) }\end{array}$ & $\begin{array}{l}\text { Gunakan sikat WC atau pembersih semua kebutuhan } \\
\text { Pastikan toilet bersih dari rambut, sampah, limbah, debu, noda, dan } \\
\text { bau. } \\
\text { Semprotkan pembersih di bawah toilet bowl dan diamkan beberapa } \\
\text { menit. Bersihkan permukaan toilet bowl pada bagian pinngirannya, } \\
\text { tempat duduknya, engsel, semua porselen. } \\
\text { Berawal dari pinggirannya, gosok bagian dalam toilet, berhati- } \\
\text { hatilah untuk tidak menyiram bahan kimia apapun pada diri Anda } \\
\text { atau di mata Anda. } \\
\text { Lap semua perangkat keras. } \\
\text { Bersihkan dan keringkan bagian luar toilet dengan seksama. } \\
\text { Siram sampai air dalam toilet bowl sampai bersih dan untuk } \\
\text { memastikan fungsinya dapat berfungsi dengan baik. } \\
\text { Pastikan toilet bekerja dengan benar. } \\
\text { Laporkan malfungsi apapun ke Housekeeping Office. } \\
\text { CATATAN: Jangan gunakan pembersih toilet bowl pada permukaan } \\
\text { lainnya. }\end{array}$ \\
\hline 13 & $\begin{array}{l}\text { Clean } \\
\text { shower } \\
\text { wall }\end{array}$ & $\begin{array}{l}\text { Menjaga } \\
\text { dinding } \\
\text { kamar } \\
\text { mandi } \\
\text { tetap } \\
\text { bersih }\end{array}$ & $\begin{array}{l}\text { d) } \\
\text { e) } \\
\text { f) } \\
\text { g) } \\
\text { h) }\end{array}$ & $\begin{array}{l}\text { Pastikan shower bebas dari rambut, puing-puing, sampah, debu, } \\
\text { noda, bau, jamur dan goresan. } \\
\text { Gunakan semua pembersih, spons dan squeegee untuk } \\
\text { membersihkan dinding dan pintu kaca. Mulailah dari atas dan } \\
\text { turunkan ke bawah. } \\
\text { Bersihkan dinding marmer dengan kain lembab dan pastikan itu } \\
\text { bebas dari noda. } \\
\text { Saat membersihkan, perhatikan sudut dan tepinya. } \\
\text { Bersihkan kepala shower dan sabun. } \\
\text { Bilas shower dengan air panas. } \\
\text { Matikan kenop shower. } \\
\text { Gunakan kain kering dan bersih untuk mengkilapkan krom dan } \\
\text { semua perlengkapan. } \\
\text { Pastikan dinding shower, lantai dan pintu dalam kondisi kering. } \\
\text { Beritahu supervisor tentang jamur atau goresan apa pun. }\end{array}$ \\
\hline 14 & Amenities & $\begin{array}{l}\text { Menjaga } \\
\text { stok } \\
\text { keleng- } \\
\text { kapan }\end{array}$ & b) & $\begin{array}{l}\text { Atur fasilitas kelengkapan (amenities) dan tempatkan sesuai } \\
\text { petunjuk properti. } \\
\text { Kembalikan persediaan dengan pengaturan standar. } \\
\text { Pastikan untuk mengganti yang lama dengan yang baru.. }\end{array}$ \\
\hline
\end{tabular}




\begin{tabular}{|c|c|c|c|}
\hline & & $\begin{array}{l}\text { kamar } \\
\text { sesuai } \\
\text { dengan } \\
\text { jumlah } \\
\text { yang } \\
\text { ditentu- } \\
\text { kan dan } \\
\text { standar }\end{array}$ & $\begin{array}{l}\text { d) Atur tata letak agar terlihat rapi, menarik dan memberikan } \\
\text { kemudahan kepada tamu untuk mempergunakannya. } \\
\text { e) Untuk kamar check-out pastikan semua fasilitas diganti, seperti } \\
\text { envelopes, stationery paper, desk stationary, postcard, notepads, } \\
\text { laundry/ dry cleaning bag, laundry slip, shoe bag, boxed soap, } \\
\text { pleaded soap, shampoo, conditioner, bath gel, body lotion, loofah } \\
\text { sponge, shower cap, toothbrush kit, emery board, cotton pads, q-tips } \\
\text { f) CATATAN: Lihat lampiran untuk penempatan yang mampu } \\
\text { memberikan kemudahan. }\end{array}$ \\
\hline 15 & $\begin{array}{l}\text { Clean } \\
\text { Furniture }\end{array}$ & $\begin{array}{l}\text { Menjaga } \\
\text { furniture } \\
\text { di } \\
\text { ruangan } \\
\text { kamar } \\
\text { tamu } \\
\text { tetap } \\
\text { bersih } \\
\text { dan } \\
\text { berada } \\
\text { pada } \\
\text { tempat } \\
\text { yang } \\
\text { sesuai } \\
\text { dengan } \\
\text { standar } \\
\text { hotel }\end{array}$ & $\begin{array}{l}\text { a) Pastikan furnitur dalam keadaan baik. } \\
\text { b) Pastikan furnitur bebas dari: debu, kotoran, sidik jari, noda, bercak. } \\
\text { c) Gunakan kain untuk membersihkan debu, apabila diperlukan } \\
\text { tambahkan pembersih khusus untuk membersihkan semua perabotan: } \\
\text { armoire/lemari, nightstands, headboard, coffee table, desk, chairs and } \\
\text { sofas, wooden legs/arms } \\
\text { d) Lap, keringkan dan buat menjadi mengkilap. } \\
\text { e) Untuk ruang check-out, buka semua laci dan keluarkan barang yang } \\
\text { ditinggalkan tamu, cek barang kemungkinan terdapat barang lost and } \\
\text { found. Bersihkan debu hingga ke bagian dalam. } \\
\text { f) Gunakan sapu bulu untuk rak dalam dan semua tempat tinggi. } \\
\text { g) Pastikan dinding tempat tidur dan tempat sandaran kepala bebas dari } \\
\text { debu. } \\
\text { h) Laporkan perabot yang rusak atau perlu diperbaiki ke koordinator } \\
\text { housekeeping. } \\
\text { i) Pastikan posisi furnitur berada ada tempat yang sesuai dengan } \\
\text { standar hotel. }\end{array}$ \\
\hline 16 & $\begin{array}{l}\text { Vacuum } \\
\text { Room }\end{array}$ & $\begin{array}{l}\text { Menjaga } \\
\text { ruangan } \\
\text { tetap } \\
\text { bersih } \\
\text { dan } \\
\text { bebas } \\
\text { dari debu }\end{array}$ & $\begin{array}{l}\text { a) Pastikan semua area termasuk lemari disedot setiap hari. } \\
\text { b) Pastikan karpet bebas dari debu, kotoran, noda. } \\
\text { c) Mulai di sudut terjauh dari pintu masuk dan jalan keluar dari ruangan } \\
\text { (hindari berlari di atas kabel vakum). } \\
\text { d) Pindahkan perabot kecil dan vakum di bawah masing-masing. } \\
\text { e) CATATAN: Jangan sekali-kali menarik kabel dari dinding kecuali } \\
\text { dengan menahan penyumbat pada soket/stop kontak. }\end{array}$ \\
\hline 17 & $\begin{array}{l}\text { Leave } \\
\text { room }\end{array}$ & $\begin{array}{l}\text { Memasti } \\
\text { kan } \\
\text { ruangan } \\
\text { dalam } \\
\text { keadaan } \\
\text { sempur- } \\
\text { na } \\
\text { sebelum } \\
\text { ditinggal } \\
\text { kan }\end{array}$ & $\begin{array}{l}\text { a) Berjalanlah keliling ruangan kamar dan periksa kembali. } \\
\text { b) Pastikan ruangan itu memiliki tampilan rapi dan semua perlengkapan } \\
\text { pembersih tidak ada di ruangan. } \\
\text { c) Tarik pintu tertutup rapat, dan pastikan pintu terkunci. } \\
\text { d) Perbarui status kamar menjadi kamar yang bersih (VC atau OC) }\end{array}$ \\
\hline 18 & $\begin{array}{l}\text { Return } \\
\text { cleaning } \\
\text { supplies }\end{array}$ & $\begin{array}{l}\text { Menjaga } \\
\text { persedia- } \\
\text { an } \\
\text { pember- } \\
\text { sih selalu } \\
\text { tersedia } \\
\text { sesuai } \\
\text { kebutuh- } \\
\text { an setiap } \\
\text { saat }\end{array}$ & $\begin{array}{l}\text { a) Kembalikan semua tas penyimpanan cleaning supplies ke } \\
\text { housekeeping office. } \\
\text { b) Pastikan semua kain kotor sudah dipisahkan dari linen yang bersih. } \\
\text { c) Pastikan tempat sampah ditempatkan di tempat sampah yang tersedia } \\
\text { dan sesuai aturan. } \\
\text { d) Pastikan caddies dimasukkan kembali pada shift PM. }\end{array}$ \\
\hline 19 & $\begin{array}{l}\text { Turn } \\
\text { keys }\end{array}$ & $\begin{array}{l}\text { Menjaga } \\
\text { kunci } \\
\text { berada di } \\
\text { tempat } \\
\text { yang }\end{array}$ & $\begin{array}{l}\text { a) Kembalikan kunci ke housekeeping office setelah sift kerja berakhir. } \\
\text { b) Tanda tangan sebagai bukti penyerahan kunci. }\end{array}$ \\
\hline
\end{tabular}




\begin{tabular}{|c|c|c|c|}
\hline & & $\begin{array}{l}\text { aman } \\
\text { pada saat } \\
\text { tidak } \\
\text { diguna- } \\
\text { kan }\end{array}$ & \\
\hline 20 & End of sift & $\begin{array}{l}\text { Mening- } \\
\text { galkan } \\
\text { jam kerja } \\
\text { dengan } \\
\text { sikap } \\
\text { yang } \\
\text { baik dan } \\
\text { berperila } \\
\text { ku yang } \\
\text { baik dan } \\
\text { benar }\end{array}$ & $\begin{array}{l}\text { a) Pastikan semua tugas selesai sebelum diperiksa dengan atasan untuk } \\
\text { izin pergi. } \\
\text { b) Kembalikan kunci master sebelum meninggalkan ruang kerja } \\
\text { housekeeping (housekeeping office). } \\
\text { c) Kembalikan pager ke housekeeping office dan tandatangan sebagai } \\
\text { bukti penyetoran } \\
\text { d) Ganti pakaian dan kembalikan seragam di bagian linen hotel. } \\
\text { e) Keluar dari pintu masuk karyawan. }\end{array}$ \\
\hline
\end{tabular}

Sumber: olah data hotel starwood, 2017

\section{Kesimpulan}

Bagian housekeeping yang memiliki tugas untuk membersihkan kamar disebut room attendant. Room attendant memiliki tugas untuk memelihara kebersihan, keindahan, dan kenyamanan tamu selama menginap di hotel. Dalam hal ini room attendant wajib menciptakan suasana kamar yang menunjukkan kebersihan (cleanliness), kenyamanan (comfortable), menarik (attractive), dan keamanan (safety).

Prosedur operasional standar yang dapat diterapkan dalam proses

\section{Daftar Pustaka}

Angela Knox, Chris Warhurst, Dennis Nickson dan Eli Dutton. 2015. More Than A Feeling: Using Hotel Room Attendants To Improve Understanding Of Job Quality. The International Journal of Human Resource Management. Vol. 26, No. 12, 1547-1567

Ben Walker. 2012. Housekeeping The Heart of Hotels. HOSPITALITY. ISSUE 23.

Schneider, M., Tucker. G., \& ScoviakLerner, M. 1999. The professional housekeeper (4thed.). New York, NY, USA: John Wiley. pembelajaran agar lulusan memahami standar kerja hotel yang semakin tinggi dalam menciptakan kamar yang memiliki nilai jual tinggi diantaranya grooming, report to manager, answer telephone, assignments, cleaning supplies caddie, entering guest room, guest in room, room cleaning order, check out room, clean floor, making bed, clean toilet, clean shower wall, amanities, clean furniture, vacuum room, leave room, return cleaning supplies, turn in keys, end of shift.

Suzanne De Treville, John Antonakis, dan Norman M. Edelson. 2005. Can Standrad Operating Procedures be Motivating? Reconciling Process Variability Issues and Behavioural Outcomes. Total Quality Management. Volume 16, Nomor 2, Pg. 231-241, March 2005. Routledge Taylor \& Francis Group 